\title{
Processing Capability of Maize Varieties Through Free Sorting and CATA Methodologies and Physicochemical Characteristics
}

\author{
Nelly M. F. Monteiro ${ }^{1}$, Noel H. Akissoe ${ }^{1}$, Laurent Adinsi ${ }^{1}$, Paul Houssou ${ }^{2}$, Polycarpe Kayode ${ }^{1}$, Mohamed \\ M. Soumanou ${ }^{3} \&$ D. Joseph Hounhouigan ${ }^{1}$ \\ ${ }^{1}$ Faculté des Sciences Agronomiques, Université d'Abomey-Calavi, Bénin, 03 BP: 2819 Jéricho Cotonou, Rep. \\ Bénin \\ ${ }^{2}$ Programme de Technologie Agricole et Alimentaire, Institut National des Recherches Agricoles du Bénin, \\ Porto-Novo, 01 BP 128 PTAA -INRAB, Porto-Novo, Bénin \\ ${ }^{3}$ Ecole Polytechnique d'Abomey-Calavi, Université d'Abomey-Calavi, 01BP: 2009 Cotonou, Benin \\ Correspondence: Noel H. Akissoe, Faculté des Sciences Agronomiques, Université d'Abomey-Calavi, Benin.
}

Tel: 229-9751-2024. E-mail: noel.akis@yahoo.fr

Received: January 29, 2017

Accepted: April 8, 2017 Online Published: May 11, 2017

doi:10.5539/jfr.v6n3p102

URL: https://doi.org/10.5539/jfr.v6n3p102

\begin{abstract}
Maize varieties have specific food processing abilities, with reference to the production of gambari-lifin, lifin, mawe and ogi, four major intermediate products in Benin. Except for the gambari-lifin, these products are widely known in the most of African countries. The recent development of gambari-lifin in relation with the maize grains quality suggests the screening of appropriate maize cultivars for minimizing failure during processing. Panelists comprising 77 maize food processors sorted fifteen maize varieties of which fourteen improved and one local ecotype, and then described each group with their own words. Additionally, 70 maize food processors performed the CATA (Check All That Apply) questions test with a list of sensory terms on the maize varieties. Furthermore, selected physicochemical and rheological parameters were determined on seven representative maize varieties. Multidimensional scaling (MDS) and hierarchical cluster analysis and multiple factorial analyses (MFA) were performed on sensory descriptors and instrumental data. Based on MDS, four groups of maize varieties were identified being specifically appropriate for one or more of these intermediate products. Grains size and weight, endosperm texture and in a lesser extent colour were the major group descriptors of maize varieties. Vitreous character or average size were positively correlated to processing yield as far as gambari-lifin is concerned while floury character was associated to "ability for pasting". This study confirms that food processors perception is very helpful and useful tools for maize breeders since it early provides consistent information for the end-uses products.
\end{abstract}

Keywords: maize, grain texture, consumer perception, gambari-lifin

\section{Introduction}

Maize based foods are major part of human diet in the most of African countries, particularly in Benin, with long tradition in processing of maize into many (about forty) end products (Nago, 1989). Most of these end products derived from four intermediate products (two fermented paste "ogi and mawe" and two flours, "lifin" and "gambari-lifin"). The quality of those intermediate products is greatly linked to the type of maize varieties. Some of these intermediate products of maize (lifin, ogi, mawe) were greatly investigated with respect to variety (Hounhouigan, 1994; Nago, Akissoe, Matencio, \& Mestres, 1997; Kameni, Kouebou, \& Dandjouma, 2007). Gambari-lifin is the maize flour made from shelled/degermed grains and it is used to prepare gel like paste/dough consumed with sauces or can partially be used in bakery and pastry to produce bread and cakes. Preliminary study on gambari-lifin (Adjile et al., 2015) was undertaken on the process and product characterization, while only four maize varieties were tested among the forty varieties commonly cultivated in Benin. In addition, other new improved maize varieties are currently under agronomic test in the research station of INA, in the North of Benin. It is necessary to concomitantly evaluate the aptitude of these maize varieties for preparing the food intermediate products (ogi, mawe, gambari-lifin, lifin) based on selected analytical and sensory methodologies. 
Traditionally, processors of a given intermediate product are able to select appropriate varieties among a range of maize offered in market. Thus, they know empirically which quality of maize varieties would fit the desirable quality of the end products. In the usual practice, processors observed the physical feature of the maize grains (colour, size, weight and form) exposed by vendors or cut the grain with their teeth in order to appreciate inside endosperm of maize before making decision to buy. This method for selecting appropriate raw materials for processing has been long established in the context where no standard method is used for marketing. As a matter of fact, processors of "ogi" or "lifin" are able to group/classify maize varieties in appropriate way for "ogi" or "lifin". In this respect, it is interesting to take into account this traditional and experienced method of selecting maize varieties earlier during genetic improvement in the research center. Basically, approach for evaluating the quality of maize varieties is based on analytical methods (Louis-Alexandre, Mestres, \& Faure, 1991; Nago et al., 1997; Kameni et al., 2007). The end-users such as processors or consumers' preferences should be complementary as one of the biggest challenges for maize breeding programs. Accordingly, correspondence can be established before processing between consumers' perception of raw material and the end products while consumers' preferences for foods and beverages have often been assessed after processing (Akusu \& Kiin-Kabari, 2015; Zare, Orsat, \& Boye, 2015; Igbabul, Iorliam, \& Umana, 2015). Concerning perceptible evaluation of the characteristics of maize, Dedehouanou et al. (2015) argued that descriptors like sensorial characteristics of maize-made meals and characteristics such as agro-morphological and harvest stage descriptors take an essential part of positive opinion on adoption. In these regards, perceptible sensory evaluation of representative samples should be complementary for selecting maize varieties with appropriate characteristics as perceived by processors and consumers using traditional selecting/checking method. This traditional checking method matches with the free sorting technique which is a rapid descriptive sensory profiling method (Nestrud \& Lawless, 2010; Dehlholm, Brockhoff, Meinert, Aaslyng, \& Bredie, 2012).

The free sorting is based on the determination of the degree of similarity between the samples (varieties) by classifying them in number of not fixed groups according to their similarity following the criteria suitable for each subject (Lawless, Sheng, \& Knoops, 1995; Nestrud \& Lawless, 2010; Dehlholm et al., 2012). One of the benefits of free sorting method is that it can be performed on relatively large samples (Abdi, Valentin, Chollet, \& Chrea, 2007). Accordingly, a large variety of foods and beverages has been evaluated with free sorting, with different scopes such as benchmarking of different products, flavor exploration and wine typicality (Maitre, Symoneaux, Jourjon, \& Mehinagic, 2010; Nestrud \& Lawless, 2010). Free Sorting technique has also been performed successfully on nonfood samples such as car fabrics (Picard, Dacremont, Valentin, \& Giboreau, 2003)

Besides the free sorting method, CATA (Check All That Apply) has been reported as a valuable and fast alternative sensory method (Ares, Deliza, Barreiro, Gimenez, \& Gambaro, 2010). With regard to the CATA method, a product is described by selecting appropriate words/terms from a given list. It is a simple and valid approach to gather information about sensory and non-sensory perception, and it is believed to have smaller effect on liking and consumer perception of the product than similar methods (Adams, Williams, Lancaster, \& Foley, 2007; Ares et al.,2010; Lado, Vicente, Manzoni,\& Ares, 2010; Giacalone, Bredie, \& Frost, 2013). It was reported that consumers using CATA profiles have shown good agreement with traditional panel developing sensory profiles (Ares et al., 2010), thus suggesting that CATA could be a valuable alternative to understand perception of maize sensory attributes. In this study, we used both free sorting and CATA methodologies together with selected physicochemical parameters to link maize varieties quality to main end-products.

The aim of the study was to screen the maize varieties based on their similarity and to understand processors' preferences, and then to assess the aptitude of maize varieties for processing the main intermediate products named gambari-lifin, ogi, mawe and lifin, with focus on gambari-lifin.

\section{Materials and Methods}

\subsection{Maize Samples}

Fifteen (15) maize varieties (Table 1) were collected (14 improved varieties at Ina research center at the North of Benin) and one local white ecotype "Gnonli" commonly used for ogi and lifin. All the maize samples were cleaned and then stored in hermetically closed buckets at $4{ }^{\circ} \mathrm{C}$ until used. 
Table 1. Selected information on maize varieties

\begin{tabular}{llll}
\hline \multicolumn{1}{c}{ Variety name } & Code & Ecotype & \multicolumn{1}{c}{ Stage in adoption } \\
\hline 2000 Syn EE W DT STR & 2000Synee & Improved & In adoption process \\
IWDC ${ }_{2}$ SYn F 2 & IWDC2SYnF2 & Improved & In test at research center \\
Bag TZE Composite 3 x 4 & BAG97 & Improved & In test at research center \\
TZ EE SR W & TZEE-W & Improved & Adopted/diffused \\
EVDT 97 STR W & EVDT97STRW & Improved & In test at research center \\
AK94 DMR ESR Y & AK94DMRESR-Y & Improved & In adoption process \\
Gnonli & Gnonli & Local & Widely used \\
FAABA/QPM & FAABA/QPM & Improved & In adoption process \\
TZE composite 3 & TZE comp 3DT & Improved & In test at research center \\
TZPB SR W & TZPBSR & Improved & Adopted/diffused \\
DMR ESR W/QPM & DMRESRW/QPM & Improved & In adoption process \\
DT SR W Co & DTSTRC3 & Improved & In test at research center \\
TZLcomp4C4 & TZL comp4C4 & Improved & In test at research center \\
TZP & TZP Tchankpo & Improved & Adopted/diffused \\
DMR ESR W & DMRESR-W & Improved & Adopted/diffused \\
\hline
\end{tabular}

\subsection{Production of Gambari-lifin}

Gambari-lifin was produced using a method as described by Adjile et al. (2015) based on dehulling, steeping, grinding, sun drying and sieving.

\subsection{Sensory Evaluation of Maize Samples Using Free Sorting and CATA Methods}

The sensory evaluation was carried out in two steps. The first has devoted to the free sorting method and the second to the CATA questions.

The free sorting method was used as described by Lawless et al. (1995). The subjects were asked to group the maize varieties according to their similarities in a way that made the most sense to them. Fifteen (15) samples of maize varieties ( $300 \mathrm{~g}$ of each) were randomized and simultaneously presented to 77 panelists (composed of $100 \%$ women). The panelists were asked to examine visually physical feature and then broke the grain if necessary to observe inside (floury and vitreous fraction). After this observation the panelists were asked to try to group the samples of maize according to their similarities, using their own personal criteria. The panelists were free to make as many groups as they desired and to put many samples they wanted in each group as long as they made more than two and less than 15 groups. The Panelists were most processors of gambari-lifin, ogi, mawe and lifin and were selected by systematic ranking at the two major towns (Cotonou and Porto-Novo) of Benin. After sorting, panelists were asked to describe the characteristics of varieties in each group. Following the first sorting task, they were also asked to select appropriate maize varieties suitable to make the intermediate maize products namely gambari-lifin, ogi, mawe and lifin, and to give the reasons why is it so. Thereafter (1-2 hours later), the fifteen buckets were randomized again and submitted to the second sorting task (replicates) so that the sorting was performed in duplicate by each panelist at the same day, but the tests were inserted with the question related to the aptitude of the varieties to make each intermediate product.

With regard to the CATA method, all maize varieties were used. The terms used in the CATA questionnaire were collected from Nago (1997), and from a preliminary investigation (Table 2). The choice was left free with processors to select the sensory attributes of the maize varieties. Seventy (70) maize food processors were asked to check if the characteristic was present or not. For this method, the samples were subjected separately to processors and in a random order. 
Table 2. Sensory terms from CATA questions and instrumental parameters used to characterize maize varieties

\begin{tabular}{lll}
\hline Variable group & Main characteristics & Type/status \\
& Small grains & Sensorial \\
Grains size & Large grains & Sensorial \\
& Medium size & Sensorial \\
& Floury & Instrumental \\
Status of endosperm & Vitreous & Instrumental \\
& Hard & Sensorial \\
& Heavy & Sensorial \\
Weight of grains & Light & Sensorial \\
& White & Sensorial \\
Grains colour & Yellow & Sensorial \\
& Bran generation /dehulling & Sensorial \\
Dehulling status & Dehulling ratio & Instrumental \\
& Water absorption perception & Sensorial \\
Water absorption & Water absorption measured & Instrumental \\
of grains & Dry matter & Instrumental \\
Processing yield & Processing yield & Instrumental \\
Aptitude for pasting & Ability for pasting & Sensorial \\
& Rheological parameters & Instrumental \\
\hline
\end{tabular}

Adapted from Nago (1997)

\subsection{Physicochemical Characteristics and Pasting Properties}

Physicochemical analyses were performed on selected maize varieties, as representatives, which were extracted from the groups obtained in the free sorting method.

\subsubsection{Characterization of the Grains Endosperm}

The vitreous, floury and germ fractions were determined by image analysis as followed: Each maize grain was longitudinally cut into two slices. Slice image was acquired with Desk Scan software (Hewlett Packard, USA) under 600 dots per inch (dpi) resolution. Brightness, contrast and image dimensions were adjusted using Paint.net v4 software. Thresholding operation between 230-250 grey levels was applied on adjusted image and measurement performed using Sigma Scan pro v5 software, giving vitreous, floury and germ fractions of a maize grain which were painted in different colours. Based on total area, the three fractions were calculated. Five replicates were assayed per maize variety.

\subsubsection{Physicochemical and Pasting Analyses}

The dry matter was determined according to American Association of Cereal Chemist method 44-15A (AACC, 1984). The pasting properties (Pasting temperature and viscosity parameters such as peak viscosity, end-viscosity, and setback value, easy of cooking) of each flour were determined as described by Adjile et al. (2015). The water absorption capacity was determined according to the method described by Akubor (2005).

The dehulling ratio was determined as fraction of the gritz portion obtained over the whole quantity of grains after dehulling $100 \mathrm{~g}$ of maize on equipment (Engelberg's shelling) for $2 \mathrm{~min}$.

\subsection{Statistical data processing}

Data from sorting were structured in the form of a similarity matrix binary ( 1 stands for two varieties set in the same group and $\mathbf{0}$ for two varieties put in different groups). A similarity matrix was obtained by summing the number of times that each pair of varieties is placed in the same group. This matrix was analyzed using multidimensional scaling (MDS) which evidenced the degree of similarity between a pair of samples. In addition, each sensory descriptor provided for groups of varieties was analyzed using Cochran's $Q$ test. Differences were significant at $\mathrm{p}<0.05$ and only significant descriptors were selected for multiple correspondence analysis. As far as CATA evaluation is concerned, Cochran's Q test was also performed. The multi-factor analysis (MFA) was performed on descriptors/characteristics and other physical parameters using the maize varieties as supplementary/illustrative variable. The Hierarchical Cluster analysis (HCA) of varieties regrouped the maize according to their similarity. These statistical analyses were carried out with XLSTAT software for Windows version 2012.5 (Adinsoft, Paris, France). 


\section{Results}

\subsection{Similarity of Maize Varieties}

The configuration resulting from multidimensional scaling revealed the global perceptive proximity of maize varieties tested by food processors (Figure 1ab). The Kruskal's stress values from the MDS analysis indicated $20.5 \%$ in replicate 1 and $19.8 \%$ in replicate 2 for the first two dimensions and then, spaces with 4 dimensions gave a good fit to the dissimilarities with their associated stress values being around 0.10 . The change in the stress in relation with the number of dimensions of the configuration was similar for both replicates, indicating a good repeatability in both experiments (Table 3). The good performance of sorting may be related to the set of samples used, since maize has many sensory attributes that interact, leading consumers naturally to use many sensory attributes for the formation of groups and description of samples (Moussaoui \& Varela, 2010). According to the configuration structure observed and the distance measured between samples in the first experiment, four groups of varieties can be formed (Figure 1a). Similar classification was established in the second experiment, except for two varieties (Gnonli and TZL comp4C4) which were found close to the two groups (Figure 1b). Spaces more than two dimensions should be helpful to differentiate these varieties. However, based on the description of sensory attributes provided by the end-users for each group, the hierarchical cluster analysis revealed four quite distinct groups (Figure 2). The different positions showed clear differences among the samples even if the consumers were not able to differentiate the local and improved maize varieties. The maize varieties BAG97, DTSTRC3, TZE comp 3 resemble each other on the one hand (group 1) the TZEE-W, 2000Synee and TZPBSR (group 2) were side by side. The AK94DMRESR-Y, Gnonli and TZP Tchankpo (group 3) were grouped in the same cluster while the DMRESR-W, DMRESRW/QPM, TZLcomp4C4, FAABA/QPM, EVDT97STRW, and IWDC2SYnF2 (group 4) were very similar.

Table 3. Changes in the stress values according to configuration dimensions

\begin{tabular}{lllll}
\hline Dimensions & 2 & 3 & 4 & 5 \\
\hline Kruskal's Stress (Rep1) & 0.205 & 0.128 & 0.100 & 0.092 \\
Kruskal's Stress (Rep2) & 0.198 & 0.132 & 0.103 & 0.091 \\
\hline
\end{tabular}

a) Configuration (Kruskal's Stress $(1)=0.205$ )

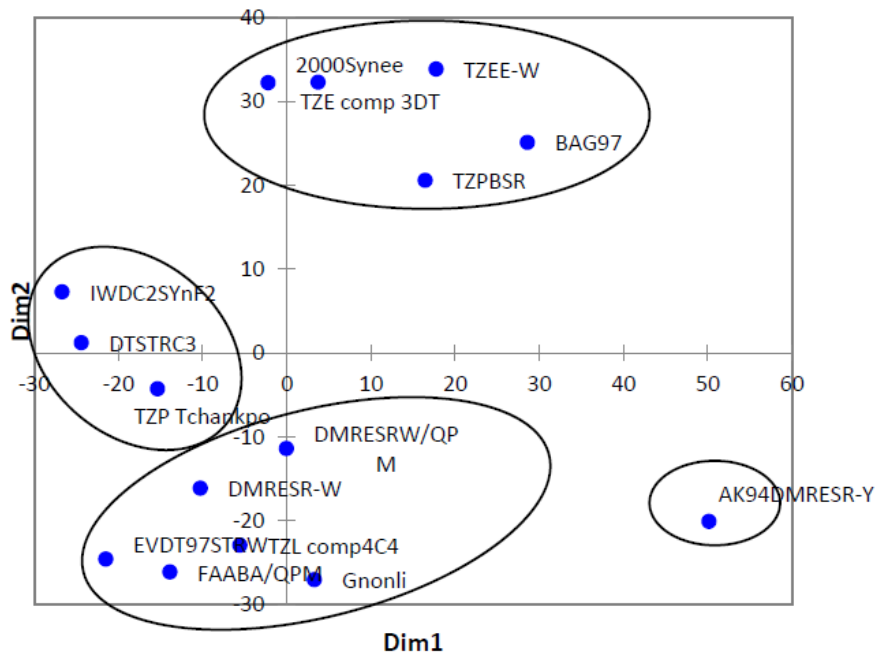




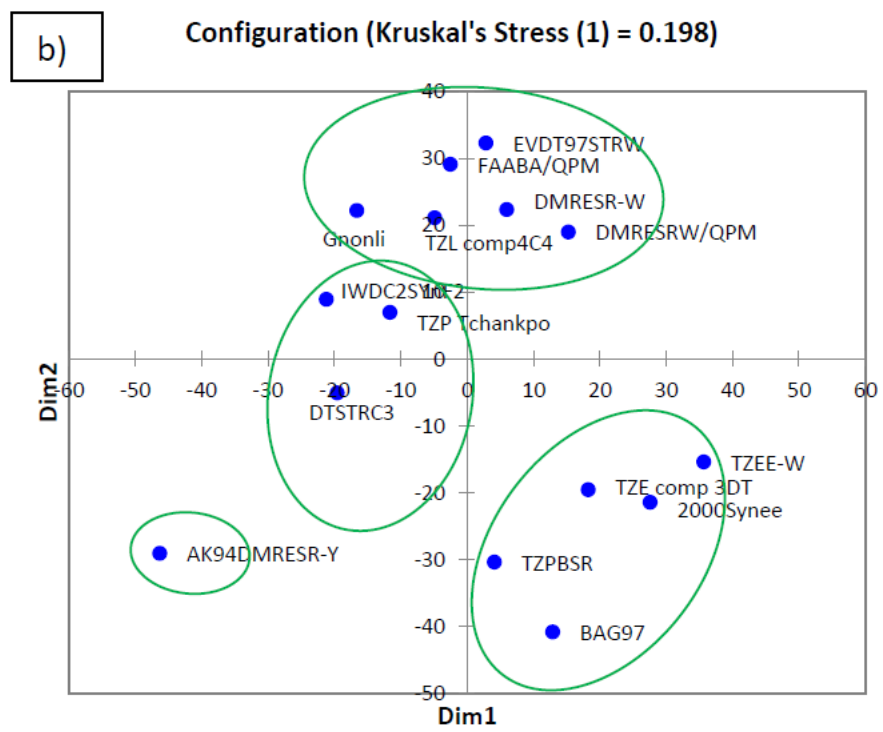

Figure 1. Maize varieties in the first two dimensions of the MSD of data from sorting (a): experiment 1 and (b): replicate 2

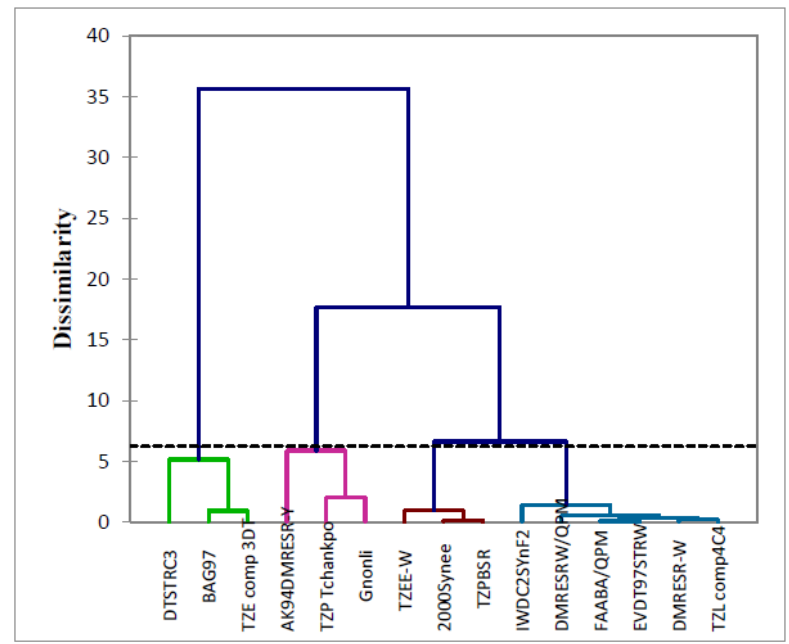

Figure 2. Dendrogram from Hierarchical Cluster analysis (HCA) of varieties

\subsection{Characteristics of Main Maize Varieties and Their End-Uses Destination}

Specific and significant descriptors with high discriminating power were associated to each group (Table 4; figure 3). Thus, the varieties of group 1 (BAG97, DTSTRC3, TZE comp 3DT) were light, and they were small sized grains or average sized in a lesser extent. They were difficult to grind and to dehull and had high fraction of bran. They were not associated to any intermediate products; they were at the opposite side to mawe and gambari-lifin (Figure 3). At the opposite, the group 4 (DMRESR-W, DMRESRW/QPM, TZLcomp4C4, FAABA/QPM, EVDT97STRW,-IWDC2SYnF2TZP) was associated to heaviness, hard grains attributes, and members of the group were easy to grind and to dehull; they can easily be processed into mawe and gambari-lifin. Maize varieties of group 2 (TZEE-W, 2000Synee and TZPBSR) were associated to descriptors such as hard grains, white, heaviness and dry-milling. They are not specified for any intermediate products but seem close to mawe and gambari-lifin. The third group (AK94DMRESR-Y, Gnonli and TZP Tchankpo) was floury, easy to grind, had low fraction of bran and average size, and members are very adapted for ogi and lifin (whole grain flour) products. Despite the proximity of AK94DMRESR-Y to this group, it is seemed far from the other members due to its yellow colour which should not be appropriate for gambari-lifin. 


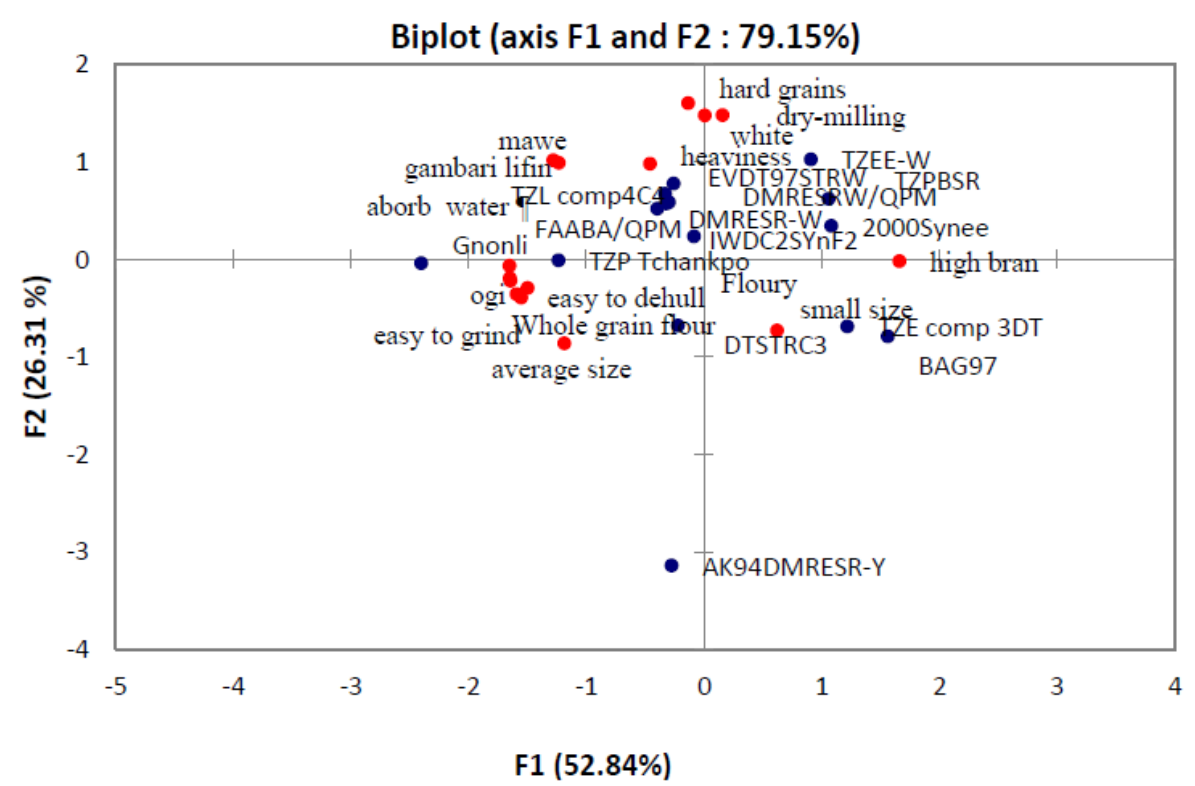

Figure 3. Relation between maize varieties, descriptors and end-products

Table 4. Descriptors associated to maize varieties (free sorting)

\begin{tabular}{lc}
\hline DESCRIPTORS & P-value \\
\hline Floury & $<0.0001$ \\
Hard grains & $<0.0001$ \\
Dry-milling & 0.000 \\
High bran & $<0.0001$ \\
Aborb quickly water II & $<0.0001$ \\
Heaviness & $<0.0001$ \\
Small size & $<0.0001$ \\
Easy to grind & $<0.0001$ \\
White & $<0.0001$ \\
Easy to dehull & $<0.0001$ \\
Gverage size & $<0.0001$ \\
Gambari-lifin & 0.000 \\
Traditional whole grain flour & $<0.0001$ \\
Ogi & $<0.0001$ \\
Mawe & 0.000 \\
\hline
\end{tabular}

\subsection{Appropriate Attributes and End-Uses Abilities of Maize Varieties (CATA)}

As far as CATA question is concerned, the frequencies in which each term was checked are presented in table 5. The most frequently used attributes to describe maize grains were heavy, white and hard. The Q Cochran's test revealed significant differences in consumers' perception of the evaluated maize varieties (Table 5). Both differences in visual characteristics (size, texture, colour) of maize grains and their aptitude/ability to make the major intermediate products (ogi, lifin, mawe and gambari-lifin) were established. Figure 4 shows the map from a correspondence factorial analysis of those characteristics related to maize varieties. Apart from BAG97, DTSTRC3 and TZEComp3DT, all other varieties were appropriate for one or more intermediate products. Thus, the group of TZPBSR, DMRESR-W, TZLComp4C4, FAABA/QPM, EVD97STRW and TZEE-W was checked appropriate for lifin (whole maize flour). In contrast to free sorting, the group 2 (TZEE-W, 2000Synee and TZPBSR) and group 3 (AK94DMRESR-Y, Gnonli and TZP Tchankpo) were very similar and were indicated for three intermediate products (ogi, mawe and gambari-lifin). Furthermore, one variety (IWDC2SYnF2TZP) was checked as appropriate for these products while in free sorting, it was perceived appropriate for two products only (mawe and gambari-lifin). 
Table 5. CATA-question: Frequencies and p-values of sensory attributes for each maize variety

\begin{tabular}{|c|c|c|c|c|c|c|c|c|c|c|c|c|c|c|c|c|}
\hline Sample code & $\begin{array}{l}\text { Small } \\
\text { size }\end{array}$ & $\begin{array}{l}\text { Large } \\
\text { size }\end{array}$ & $\begin{array}{l}\text { Average } \\
\text { size }\end{array}$ & Floury & Vitreous & Hardness & Heaviness & Light & White & Yellow & $\begin{array}{l}\text { High } \\
\text { bran }\end{array}$ & $\begin{array}{l}\text { Aborb } \\
\text { quickly } \\
\text { water }\end{array}$ & $\begin{array}{l}\text { Apt } \\
\text { gambarilifin }\end{array}$ & Apt_lifin & Apt_ogi & Apt_mawe \\
\hline BAG97 & 65 & 5 & 0 & 57 & 13 & 68 & 34 & 36 & 70 & 0 & 24 & 53 & 2 & 17 & 2 & 5 \\
\hline TZPBSR & 0 & 69 & 1 & 42 & 28 & 70 & 69 & 1 & 70 & 0 & 43 & 33 & 12 & 11 & 17 & 7 \\
\hline DMRESRW/QPM & 0 & 39 & 31 & 44 & 26 & 70 & 69 & 1 & 70 & 0 & 40 & 33 & 12 & 9 & 17 & 12 \\
\hline DMRESR-W & 1 & 51 & 18 & 46 & 24 & 69 & 68 & 2 & 70 & 0 & 38 & 26 & 22 & 7 & 19 & 17 \\
\hline TZL comp4C4 & 4 & 45 & 21 & 52 & 18 & 70 & 66 & 4 & 70 & 0 & 43 & 39 & 0 & 17 & 2 & 5 \\
\hline DTSTRC3 & 67 & 3 & 0 & 52 & 18 & 65 & 29 & 41 & 70 & 0 & 19 & 56 & 15 & 6 & 20 & 11 \\
\hline TZE comp 3DT & 32 & 8 & 30 & 58 & 12 & 69 & 53 & 17 & 70 & 0 & 45 & 62 & 0 & 3 & 12 & 4 \\
\hline FAABA/QPM & 0 & 58 & 12 & 40 & 30 & 69 & 68 & 2 & 70 & 0 & 48 & 41 & 6 & 19 & 7 & 7 \\
\hline Gnonli & 2 & 28 & 40 & 49 & 21 & 70 & 68 & 2 & 70 & 0 & 42 & 32 & 25 & 13 & 24 & 21 \\
\hline EVDT97STRW & 0 & 66 & 4 & 43 & 27 & 69 & 69 & 1 & 70 & 0 & 51 & 40 & 14 & 3 & 16 & 13 \\
\hline TZEE-W & 0 & 61 & 9 & 48 & 22 & 69 & 69 & 1 & 70 & 0 & 38 & 29 & 0 & 3 & 12 & 4 \\
\hline AK94DMRESR-Y & 1 & 32 & 37 & 63 & 7 & 70 & 69 & 1 & 0 & 70 & 34 & 54 & 23 & 3 & 20 & 18 \\
\hline P-value* & 0.0001 & 0.0001 & 0.001 & 0.001 & 0.0001 & 0.01 & 0.01 & 0.001 & 0.0001 & 0.0001 & 0.0001 & 0.0001 & 0.0001 & 0.0001 & 0.0001 & 0.0001 \\
\hline
\end{tabular}

* Q Cochan's test

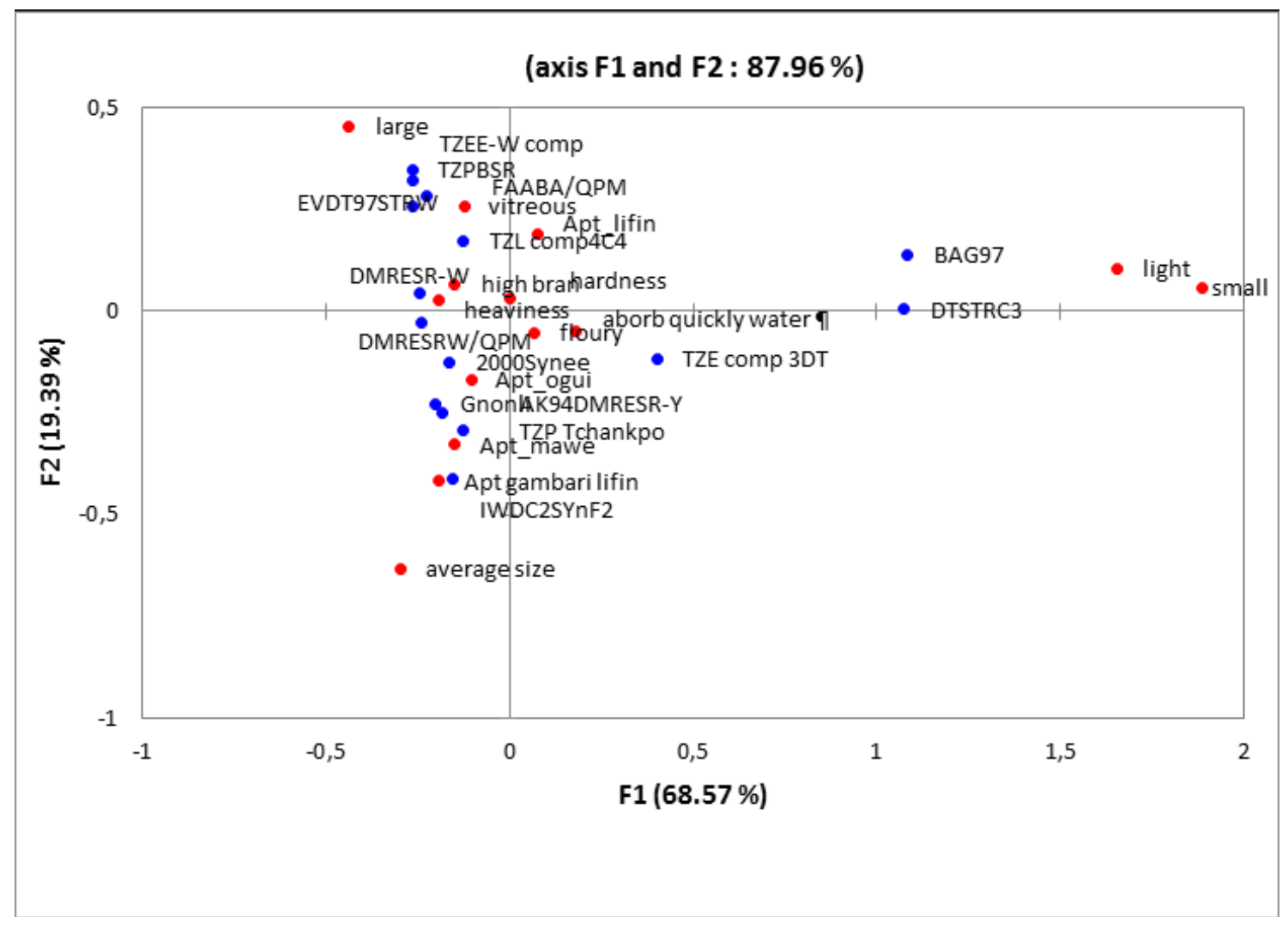

Figure 4. Correspondence factorial analysis of descriptors and maize varieties

\subsection{Relation between Perceptible, Physical and Rheological Characteristics}

Two maize varieties were reasonably chosen from each of the four groups obtained in the free sorting; but one group was constituted of one sample. Thus, seven samples were characterized in laboratory to evaluate the relation between perceptible and instrumental parameters. Great variability was observed in vitreous, floury and germs fractions of maize grains (Table 6). Some maize varieties (BAG97, TZPBSR and DTSTRC3) were vitreous, with vitreous fraction around 50\% the total endosperm while the others seemed semi-friable. There was a positive and significant relation between floury fraction and the yield in gambari-lifin and the dehulling ratio (Figure 5). 
Table 6. Physical properties of selected representative maize varieties and their ability for gambari-lifin

\begin{tabular}{llllllll}
\hline Samples & $\begin{array}{l}\text { Floury } \\
\text { fraction } \\
(\%)\end{array}$ & $\begin{array}{l}\text { Vitreous } \\
\text { fraction } \\
(\%)\end{array}$ & $\begin{array}{l}\text { Germs } \\
\text { fraction } \\
(\%)\end{array}$ & $\begin{array}{l}\text { Water } \\
\text { absorption } \\
(\%, \mathrm{w} / \mathrm{w}, \mathrm{db})\end{array}$ & $\begin{array}{l}\text { Dry } \\
\text { mater } \\
(\%, \mathrm{db})\end{array}$ & $\begin{array}{l}\text { Yieldin } \\
\text { gambari-lifin } \\
(\%, \mathrm{w} / \mathrm{w})\end{array}$ & $\begin{array}{l}\text { Dehulling } \\
\text { ratio } \\
\mathrm{w} / \mathrm{w})\end{array}$ \\
\hline BAG97 & 33.4 & 52.4 & 14.2 & 15.3 & 88.4 & 56.7 & 79.9 \\
2000Synee & 37.2 & 45.3 & 15.4 & 14.9 & 86.7 & 61.4 & 81.0 \\
TZPBSR & 31.1 & 51.5 & 17.4 & 15.6 & 87.4 & 57.1 & 76.5 \\
DMRESRW/QPM & 43.8 & 43.4 & 12.9 & 21.6 & 87.4 & 62.1 & 85.4 \\
DTSTRC3 & 34.3 & 48.8 & 16.9 & 15.6 & 88.6 & 63.3 & 84.7 \\
AK94DMRESR-Y & 43.3 & 40.0 & 16.7 & 16.6 & 87.4 & 69.7 & 86.2 \\
IWDC2SYnF2 & 40.1 & 40.7 & 19.2 & 16.4 & 86.0 & 68.8 & 86.4 \\
\hline
\end{tabular}

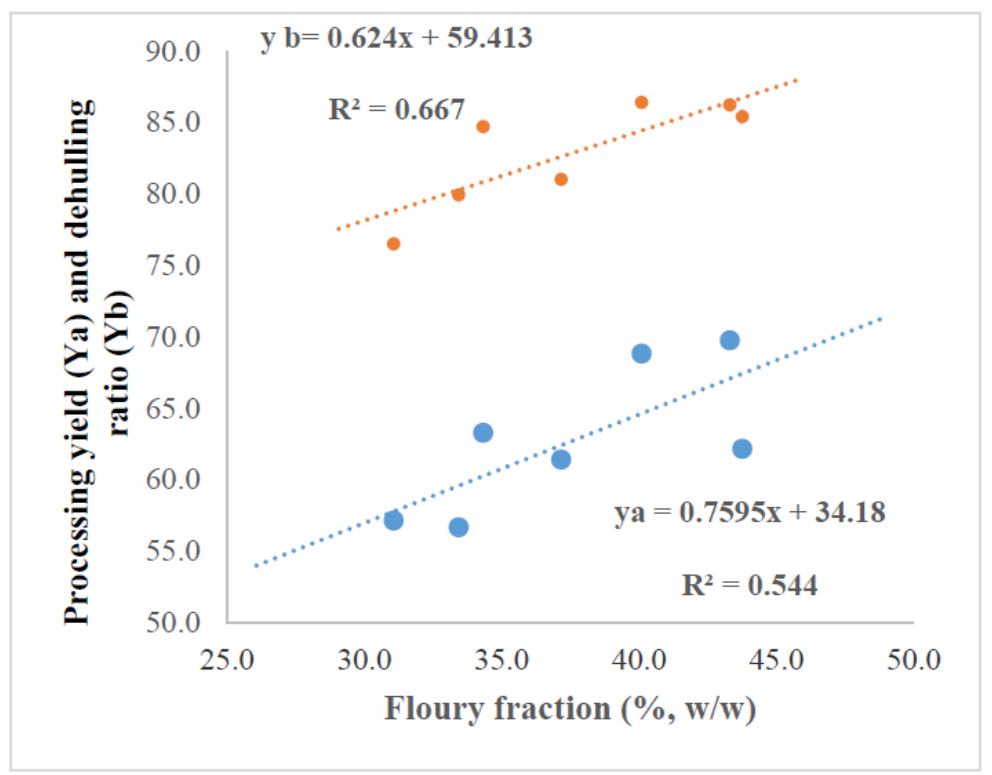

Figure 5. Relation between floury fraction and (Ya) processing yield and $(\mathrm{Yb})$ dehulling ratio

The variable groups (grains size, grains weight and grains colour) from CATA questions alone and combined with instrumental characteristics (status of endosperm, dehulling status, water absorption of grains, viscosity) and processing yield were gathered in Multiple Factorial Analysis (MFA) (Figure 6). Strong correlations between these variable groups were observed with RV values very high. The RV coefficient between the variable groups were all greater than 0.72 (Table 7) except for colour and processing yield.

Table 7. Correlation (RV) between sensory terms from CATA questions

\begin{tabular}{|c|c|c|c|c|c|c|c|c|c|c|}
\hline & $\begin{array}{l}\text { Grains } \\
\text { size }\end{array}$ & $\begin{array}{l}\text { Status of } \\
\text { endosperm }\end{array}$ & $\begin{array}{l}\text { Grains } \\
\text { weigh }\end{array}$ & $\begin{array}{l}\text { Grains } \\
\text { colour }\end{array}$ & $\begin{array}{l}\text { Dehulling } \\
\text { status }\end{array}$ & $\begin{array}{l}\text { water } \\
\text { absorption } \\
\text { of grains }\end{array}$ & $\begin{array}{l}\text { Processing } \\
\text { yield }\end{array}$ & Viscosity & Ecotype & AFM \\
\hline \multicolumn{11}{|l|}{ Grains size } \\
\hline Status of endosperm & 0.58 & & & & & & & & & \\
\hline Grains weigh & 0.89 & 0.40 & & & & & & & & \\
\hline Grains colour & 0.07 & 0.34 & 0.08 & & & & & & & \\
\hline Dehulling status & 0.65 & 0.56 & 0.49 & & & & & & & \\
\hline $\begin{array}{l}\text { Water absorption } \\
\text { of grains }\end{array}$ & 0.63 & 0.54 & 0.61 & 0.08 & 0.46 & & & & & \\
\hline Processing yield & 0.33 & 0.72 & 0.12 & 0.37 & 0.51 & 0.17 & & & & \\
\hline Viscosity & 0.55 & 0.52 & 0.45 & 0.07 & 0.68 & 0.52 & 0.18 & & & \\
\hline Ecotype & 0.548 & 0.686 & 0.408 & 0.408 & 0.551 & 0.617 & 0.408 & 0.682 & & \\
\hline AFM & 0.84 & 0.76 & 0.72 & 0.35 & 0.80 & 0.73 & 0.55 & 0.77 & 0.76 & \\
\hline
\end{tabular}


The analysis of the group related to the size of grains (with character small, large and average size of grains) showed that IWDC2SYnF2 and TZPBSR were associated to average large size grains respectively. In opposite to 2000Synee, DMRESRW/QPM and AK94DMRESR-Y, the samples named BAG97 and DTSTRC3 had small size grains (Figure 6A.).

As far as the status of endosperm (Figure 6B.), the term floury was opposite side to vitreous. The majority of varieties (57\%) were vitreous; only AK94DMRESR-Y was slightly floury. The varieties DMRESRW/QPM and IWDC2SYnF2 appeared mid-floury and mid-vitreous. Concerning the variable colour of grains, all maize varieties, except AK94DMRESR-Y, were white (Figure 6C.). Regarding the maize weigh (Figure 6D.), the varieties BAG97 and DTSTRC3 were perceived light while TZPBSR, DMRESRW/QPM, 2000Synee, IWDC2SYnF2 and AK94DMRESR-Y were heavy.

With regards to dehulling status (Figure 6E.), the "amount of bran generated and the ratio of dehulling" were opposite, suggesting that maize varieties with high amount of bran give low ratio of dehulling. Accordingly, the varieties AK94DMRESR-Y, BAG97, DTSTRC3, IWDC2SYnF2, 2000Synee and DMRESRW/QPM had high dehulling ratio during the processing in contrary to TZPBSR.

Concerning the water absorption of grains (Figure 6F), the variety DMRESRW/QPM absorbed greatly water with the ratio of water absorption measured higher than for all others variety. The varieties IWDC2SYnF2, AK94DMRESR-Y, DTSTRC3, DMRESRW/QPM and 2000Synee had a high processing yield (Figure 6G.).

With respect to pasting properties (Figure $6 \mathrm{H}$ ), the first axis separated varieties into two groups: those having good pasting properties (BAG97, IWDC2SYnF2, DMRESRW/QPM and AK94DMRESR-Y) and those with bad pasting properties (DTSTRC3, TZPBSR and 2000Synee).

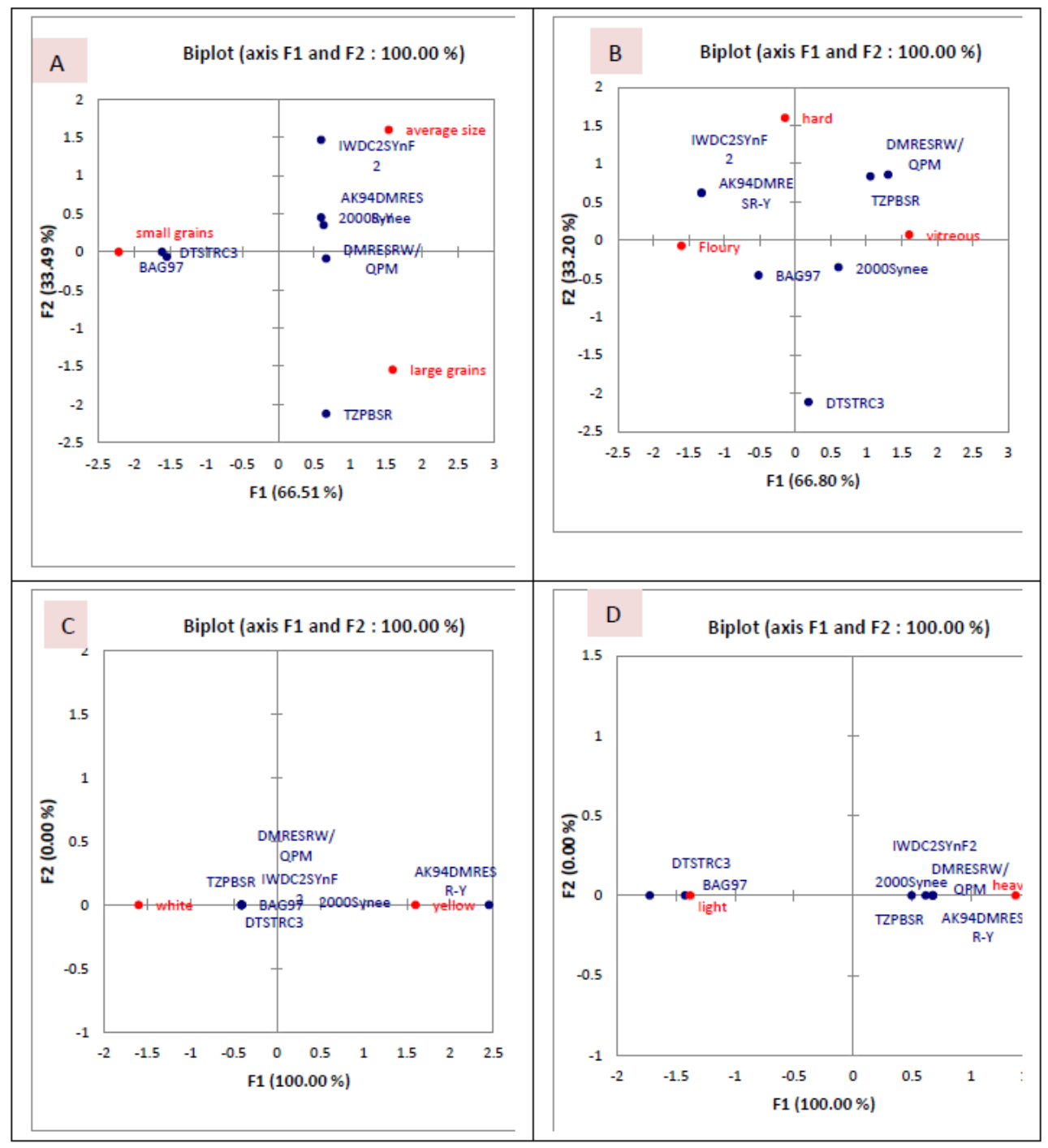




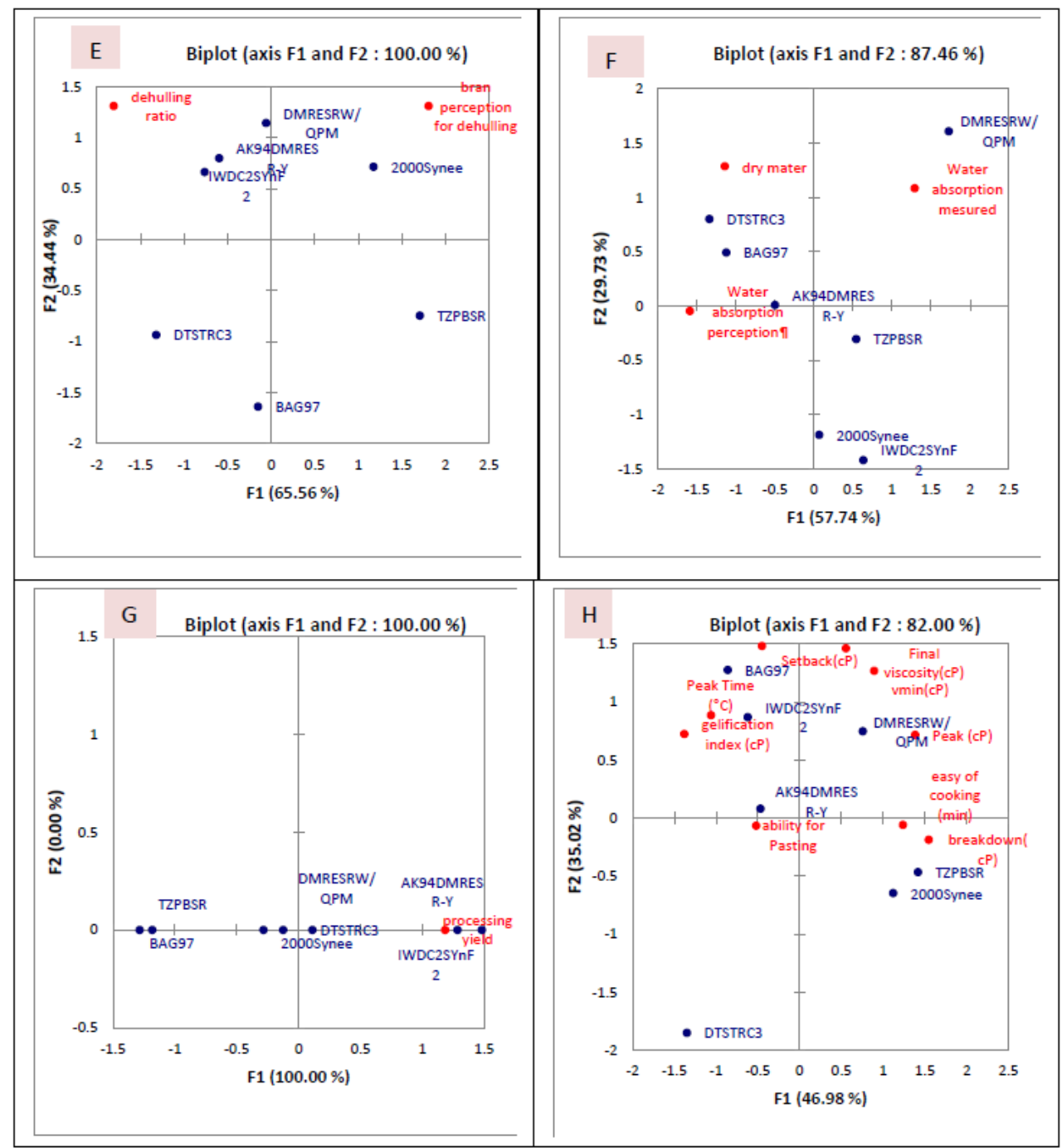

Figure 6. Multiple factor analysis individual plots using CATA counts: correlation loadings plot of grains size (A), Status of endosperm (B), Grains colour (C), Grains weigh (D), Dehulling status (E), water absorption of grains $(\mathrm{F})$, processing yield $(\mathrm{G})$, Ability for pasting $(\mathrm{H})$

\section{Discussion}

The food processors (end-users) sorting maps are consistent for the two replicates in this specific case where tactile and visual senses are used for profiling maize grains. Consistent and similar results were found through both methodologies (CATA and free sorting), with a little difference. Free sorting showed four clusters of varieties while CATA questions revealed three groups, the group 2 in free sorting (TZEE-W, 2000Synee and TZPBSR) and group 3 (AK94DMRESR-Y, Gnonli and TZP Tchankpo) being similar in the case of CATA. As far as free sorting is concerned, the Kruskal's stress values indicate that food processors had a control in the choice of the maize varieties they used. Indeed, there is a great variability in quality of corn cultivated in Benin with regard to their physical and visual characteristics. Thus, the maize varieties are very easy to differentiate; this reinforces the stability in the two replicates with four groups of varieties identified according to processors' descriptions. Chollet and Valentin (2000) showed that MDS configurations differ between two repetitions within a delay of 20 min, especially for trained subjects. In our case, the appearance of maize grains may have facilitated for consistency in clustering, whereas Chollet and Valentin (2000) used beers which were quite close in aspect. Additional studies should assess the performance of sorting variations, such as offering a list of attributes to help consumers to form groups (Chollet, Lelièvre, Abdi, \& Valentin, 2011). The similarity among the replications is highlighted by the RV coefficients; all RV coefficients were greater than 0.72 indicating good agreement among the multidimensional perceptual spaces. Nevertheless, the low RV coefficients of colour and ecotype indicate 
that the panelists are using different criteria to determine the overall degree of similarity between the varieties.

Furthermore, the group 4 (in sorting task) mainly includes the improved varieties which are most vitreous, with large and hard grains, containing much bran. They do not absorb water quickly and have high dense grains. The varieties of group 2 are easy to grind while the majority of group 4 are difficult to grind. These observations were agreed with Nago (1997) who reported that the improved varieties were vitreous with large and hard grains. According to Mestres, Nago, Hounhouigan, Akissoe, \& Davrieux (2001) and Nago (1997) the heavier is the corn grain the more vitreous is its endosperm. In addition, the hard grains require more time and force for their grinding (Nago, 1997). The grains rather the hard grains are adapted to technologies calling upon degerming (production of gritz) while the friable grains will be easily transformed (Mestres et al., 2001) into whole-maize grain flour (lifin). The varieties of group 2 are small sized grains while varieties of group 4 are maize of middle size (Gnonli). Maize varieties of big size include (2000Synee, TZPBSR, DMRESR, TZL comp4C4, FAABA, TZEE-W and EVDT97STRW). According to Mestres et al. (2001) the varieties with small grains are farinaceous while the large cultivars are vitreous.

The processing aptitudes of the maize varieties as described by food processors seem to be associated mainly to the physical and endosperm characteristics of their grains. In this case, food producers' sorting task can be used for the preference mapping of maize varieties end-uses. This method assesses the major end-uses characteristics of the grain in few minutes with a precision close to that of the traditional checking methods, in preserving intact the sample. This study supported the consistency of free sorting methods in selection of maize in markets. It should be helpful for maize breeders who can associate food processors perception instead of analytical methods.

The multiple factor analysis of individual plots using CATA counts indicates significant correlations between sensory terms and maize varieties. Therefore, the grains size and weight and the endosperm texture affect processing abilities of varieties. Additionally, the positive and direct relation between floury fraction and the yield in gambari-lifin and the dehulling ratio could help for better selecting appropriate maize varieties.

\section{Conclusion}

Free sorting was quite efficient to obtain a sensory mapping of maize varieties. However, CATA questions is complementary to free sorting in this study since some descriptors which are absent during the individual description of maize group are selected in the list of sensory terms provided during CATA. The CATA questions associated with the free sorting allowed handling consistent sensory attributes and end-uses destination of maize varieties, suggesting that sensory methodologies based on the consumers' perception may be used in the initial stage of development of new maize varieties. The perception of food processors based on visual, tactile and endosperm texture should be an alternative and short way for maize breeders.

\section{Acknowledgements}

We are grateful to West Africa Agricultural Productivity Program (WAAPP) who has financially supported and contributed the research from which the manuscript is derived and others colleagues for many helpful comments on earlier versions of these notes.

\section{References}

AACC. (1984). Approved method of the American Association of Cereal Chemist, St. Paul, MN.

Abdi, H., Valentin D., Chollet S., \& Chrea, C. (2007). Analyzing assessors and products in sorting tasks: DISTATIS, theory and applications. Journal of Food Quality and Preference, 18, 627-640. https://doi.org/10.1016/j.foodqual.2006.09.003

Adams, J., Williams, S., Lancaster, B., \& Foley, M. (2007). Advantages and uses of check-all-that-apply response compared to traditional scaling of attributes for salty snacks. In 7th Pangborn sensory science symposium, Hyatt Regency. Pp 12-418, August 16th 2007, Minneapolis, MN, USA.

Adjile, A. N., Houssou, A. P. F., Monteiro, N., Fainou, M. C., Akissoe, N. H., \& Toukourou, F. (2015). Caractérisation du procédé de gambari-lifin (farine de maïs décortiqué-dégermé) et influence de la variété de maïs sur la qualité physicochimique et rhéologique. Nature \& Technology., Agronomic \& Biological Sciences B (12). http://www.univ-chlef.dz/revueNatec/Issue12_B.html

Akubor, P. I. (2005). Functional properties of soybean-corn-carrot flour blends for cookie production. Journal of Food Science and Technology, 42, 303-307.

Akusu, M. O., \& Kiin-Kabari, D. B. (2015).Comparative Studies on the Physicochemical and Sensory Properties of Watermelon (Citrulluslanatus) and Melon (Citrullus vulgaris) Seed Flours Used in "EGUSI" Soup Preparation. Journal of food research, 4(5), 1-8. https://doi.org/10.5539/jfr.v4n5p1 
Ares, G., Deliza, R., Barreiro, C., Gimenez, A., \& Gambaro, A. (2010). Comparison of two sensory profiling techniques based on consumer perception. Journal of Food Quality and Preference, 21, 417-426. https://doi.org/10.1016/j.foodqual.2009.10.006

Chollet, S., \& Valentin D. (2000). Le degré d'expertise a-t-il une influence sur la perception olfactive? Quelques éléments de réponse dans le domaine du vin. L'année physiologique, 100, 11-36.

https://doi.org/10.3406/psy.2000.28625

Chollet, S., Lelièvre, M., Abdi, H., \&Valentin, D. (2011). Sort and beer: Everything you wanted to know about the sorting task but did not dare to ask. Journal of Food Quality and Preference, 22, 507-520. https://doi.org/10.1016/j.foodqual.2011.02.004

Dedehouanou, H., Affokpon, A., Akissoe, N., Yallou, C. G., Rachidatou, S., Ahounou, J. L., Akonde, F. X., Badou, A., \& Sagbohan, J. (2015). Caractérisation perceptive des variétés hybrides chinoises du maïs: la sélectivité sensorielle est-elle déterminante au Bénin. European scientific journal, 11(30), 1857-7431. http://www.eujournal.org/index.php/esj/issue/view/204

Dehlholm, C., Brockhoff, P. B., Meinert, L., Aaslyng, M. D., \& Bredie, W. L. P. (2012). Rapid descriptive sensory methods - Comparison of Free Multiple Sorting, Partial Napping, Napping, Flash Profiling and conventional profiling. Journal of Food Quality Preference, 26, 267-277. https://doi.org/10.1016/j.foodqual.2012.02.012

Giacalone, D., Bredie, W. L. P., \& Frost, M. B. (2013). "All-in-one test" (AI1): A rapid and easily applicable approach to consumer product testing. Journal of Food Quality Preference, 27(2), 108-119. https://doi.org/10.1016/j.foodqual.2012.09.011

Hounhouigan, D. J. (1994). Fermentation of maïze (Zea mays L.) meal for mawe production in Benin: Physical, chemical and microbiological aspects. Ph.D Thesis, Agric. Univ. Wageningen, the Netherlands, p 99.

Igbabul, B. D., Iorliam, B. M., \& Umana. E. N. (2015). Physicochemical and Sensory Properties of Cookies Produced From Composite Flours of Wheat, Cocoyam and African Yam Beans. Journal of food research, 4(2), 150-158. https://doi.org/10.5539/jfr.v4n2p150

Kameni, A., Kouebou, C. C., \& Dandjouma, A. A. K. (2007). Processing properties of grains from some maize cultivars introduced on-farm in the sudano sahelian zone of Cameroon. African. Journal of Food, Agriculture, Nutrition and. Developpement., 7(2). http://www.ajol.info/index.php/ajfand/issue/view/13961

Lado, J., Vicente, E., Manzoni, A., \& Ares, G. (2010). Application of a check-all-that apply question for the evaluation of strawberry cultivars from a breeding program. Journal of Science. Food Agricuture, 90, 2268-2275. https://doi.org/10.1002/jsfa.4081

Lawless, H. T., Sheng, N., \& Knoops, S. S. C. P. (1995). Multidimensional-scaling of sorting data applied to cheese perception. Journal of Food Quality and Preference, 6(2), 91-98. https://doi.org/10.1016/0950-3293(95)98553-U

Louis-Alexandre, A., Mestres, C., \& Faure J. (1991). Measurement of endosperm vitreousness of corn :A quantitative method and its application to African cultivars. Cereal chemistry, 68(6), 614-617. http://www.aaccnet.org/publications/cc/backissues/1991/Pages/Number6.aspx

Maitre, I., Symoneaux, R., Jourjon, F., \& Mehinagic, E. (2010). Sensory typicality of wines: How scientists have recently dealt with this subject. Journal of Food Quality and Preference, 21, 726-731. https://doi.org/10.1016/j.foodqual.2010.06.003

Mestres, C., Nago, M., Hounhouigan, J., Akissoe, N., \& Davrieux, F. (2001). Qualité comparée des grains de maïs Béninois issu des écotypes locaux et des cultivars améliorés: Mise au point de tests rapides de sélection. Actes de l'atelier scientifique, 1, 187-194.

Moussaoui, K. A., \& Varela, P. (2010). Exploring consumer product profiling techniques and their linkage to a quantitative descriptive analysis. Journal of Food Quality and Preference, 21, 1088-1099. https://doi.org/10.1016/j.foodqual.2010.09.005

Nago, C. M. (1989). Technologies traditionnelles et alimentation au Bénin: aspects techniques, biochimiques et nutritionnels. Cotonou, Bénin, (unpublished dissertation)Université Nationale du Bénin, 222.

Nago, C. M. (1997). La transformation alimentaire traditionnelle du maïs au Bénin: détermination des caractéristiques physico-chimiques des variétés en usage ; relations avec l'obtention et la qualité des principaux produits dérivés. Thèse de Doctorat es-Sciences., UFR Biochimie., Université de Paris 7, 571. 
Nago, M., Akissoe, N., Matencio, F., \& Mestres, C. (1997). End use quality of some African corn kernels1. Physico-chemical characteristics of kernels and their relationship with the quality of "lifin", a traditional whole dry-milled maize flour from Benin. Journal of Agricultural and Food Chemistry, 45(3), 555-564. https://doi.org/10.1021/jf9507957

Nestrud, M. A., \& Lawless, H. T. (2010). Perceptual mapping of apples and cheeses using projective mapping and sorting. Journal of sensory studies, 25(3), 390-405.

Picard, D., Dacremont, C., Valentin, D., \& Giboreau, A. (2003). Perceptual dimensions of tactile textures. ActaPsychologica, 114(2), 165-184. https://doi.org/10.1016/j.actpsy.2003.08.001.

Zare, F., Orsat, V., \& Boye J. I. (2015). Functional, Physical and Sensory Properties of Pulse Ingredients Incorporated into Orange and Apple Juice Beverages. Journal of food research, 4(5), 143-156. https://doi.org/10.5539/jfr.v4n5p143

\section{Copyrights}

Copyright for this article is retained by the author(s), with first publication rights granted to the journal.

This is an open-access article distributed under the terms and conditions of the Creative Commons Attribution license (http://creativecommons.org/licenses/by/4.0/). 